\title{
Trophic and fishery interactions between Pacific hake and rockfish: effect on rockfish population rebuilding times
}

\author{
Chris J. Harvey ${ }^{1, *}$, Kevin Gross ${ }^{2}$, Victor H. Simon ${ }^{1}$, James Hastie ${ }^{1}$ \\ ${ }^{1}$ Fishery Resource Analysis and Monitoring Division, Northwest Fisheries Science Center, NOAA Fisheries, \\ 2725 Montlake Blvd. E, Seattle, Washington 98112, USA \\ ${ }^{2}$ Biomathematics Program, North Carolina State University, Box 8203, Raleigh, North Carolina 27695, USA
}

\begin{abstract}
Several species of overfished Pacific rockfish (genus Sebastes) are incidentally caught in the fishery targeting Pacific hake Merluccius productus. Juvenile rockfish also comprise a small amount of Pacific hake diets. We used 2-species, age-structured models to estimate how prey selectivity by Pacific hake, life history and population structure of rockfish, spatiotemporal overlap, and fishery closures might affect the time required to rebuild overfished rockfish populations to $40 \%$ of unfished spawning stock biomass. As prey selectivity increased, rebuilding time increased moderately for widow rockfish $S$. entomelas and darkblotched rockfish $S$. crameri, and more sharply for canary rockfish $S$. pinniger. Darkblotched rockfish were the least sensitive to Pacific hake predatory selectivity, which was likely related to their rarity in Pacific hake diets, not their stochastic reproductive success. Spatiotemporal overlap between rockfish and Pacific hake also increased rebuilding times, primarily because of higher rockfish bycatch, not predation. Early fishery closures and Pacific hake predation had an interactive effect that prolonged widow and canary rockfish rebuilding times, partly as a function of model assumptions and partly because fishery closures led to increased predation on juvenile rockfish. Because an ecosystem-based approach to fisheries management involves considering the influence of ecological factors on fish populations, models that examine interactions between depleted species and predatory species are essential. In this case, it appears that overfished rockfish rebuilding times can be significantly affected by the dynamics of a key predator, but also that the predatory effect can be mitigated by effective bycatch control.
\end{abstract}

KEY WORDS: Predator-prey interactions $\cdot$ Bycatch $\cdot$ Recovery plans $\cdot$ Ecosystem-based fisheries management $\cdot$ Climate variability $\cdot$ Mortality

\section{INTRODUCTION}

An inescapable reality of commercial fisheries is that they impact non-target organisms. These impacts include habitat degradation caused by bottom-contact gears (Hall 1999), depletion of target species that are important prey for non-target species (Tasker et al. 2000, DeMaster et al. 2001), and discarding of offal that can increase scavenger populations (Jennings et al. 2001). Perhaps the most important direct impact on non-target species is incidental harvest (bycatch), which is a major source of mortality. For example, the ratio of discarded biomass to landed biomass is $8 \%$ globally (Kelleher
2005), and $28 \%$ in the United States (Harrington et al. 2005). Reducing bycatch is a key element of most prescriptions for ecosystem-based management of fisheries (e.g. NMFS 1999, NRC 1999, Sissenwine \& Murawski 2004). If non-target species become too depleted, management of targeted species may be changed in order to reduce non-target bycatch. This strategy, known as 'weak stock management' (Hilborn 2004), is often employed in mixed-stock fisheries. The intent of the strategy is to rebuild the depleted species while maintaining a viable fishery for the more abundant target species.

Here, we consider how these factors might influence groundfish along the United States Pacific coast, where 
many species of rockfish Sebastes spp. are incidentally caught by gear targeting more abundant species. Rockfish may be ill suited to handle fishing mortality rates that are sustainable for other groundfish species: they are long lived, late maturing, and have low adult natural mortality (Parker et al. 2000). Several species have spawning stock biomasses (SSB) below $25 \%$ of the estimated unfished level, and have thus been declared overfished. These species will be managed according to a formal rebuilding plan until their SSBs reach at least $40 \%$ of unfished SSB, which is used as a proxy for the biomass at which maximum sustainable yield ( $B_{\mathrm{MSY}}$ ) is attained (PFMC 2003). The biology underlying a rebuilding plan is primarily single species in nature, drawing from a stock assessment and not accounting for the dynamic nature of species interactions. During the rebuilding period, targeted fishing mortality and allowable bycatch mortality are reduced to precautionary levels. Due to their long generation times and the socioeconomic need to keep other fisheries open (thus leading to bycatch), most overfished rockfish will require decades to rebuild to $40 \%$ of unfished SSB (PFMC 2003).

The midwater trawl fishery for Pacific hake Merluccius productus, which lands more biomass than any other fishery on the United States Pacific coast, incidentally catches many rockfish. This includes widow Sebastes entomelas, canary $S$. pinniger, and darkblotched $S$. crameri rockfish (PFMC 2003), 3 overfished species with contrasting life-history traits (Table A1 in Appendix 1). Current estimates of these species' respective SSBs are $31,<10$, and $<17 \%$ of unfished biomass (He et al. 2005, Methot 2005, Rogers 2005). Managers have taken many actions to limit the take of rockfish in the Pacific hake fishery, such as precautionary allowable bycatch levels and a much higher degree of observer coverage in Pacific hake fleets than in other groundfishing fleets (PFMC 2003). The fishing industry has been proactive by avoiding fishing in areas known to be important habitat for overfished species, particularly canary rockfish (e.g. Appendix C of PFMC 2004). However, as recently as 2007, the Pacific hake fishery in the United States was closed several months earlier than normal because the fishery reached the bycatch limit for widow rockfish.

If we consider an ecosystem-based approach to managing and conserving overfished rockfish, however, we must evaluate sources of mortality besides bycatch. Survival through the earliest life stages may be critical to the strength of a rockfish year class, and thus underpin its contribution to the species' population status (e.g. Sakuma et al. 2006). One potential source of mortality at the early life stages is predation by Pacific hake, an abundant and opportunistic predator. Pacific hake mainly feed on euphausiids and schooling fish such as northern anchovy Engraulis mordax, Pacific herring Clupea harengus, and myctophids, and only a small amount of their diet is believed to be juvenile rockfish (Outram \& Haegle 1972, Livingston 1983, Buckley \& Livingston 1997). From the perspective of a prey species, however, the sheer abundance of Pacific hake may result in significant predation mortality, even if the prey is relatively rare in the hake diet (Rexstad \& Pikitch 1986). In addition, there may be episodes of greater predation. Gotshall (1969) surveyed Pacific hake stomachs for $2 \mathrm{yr}$ in the mid-1960s and found that $>10 \%$ of the identifiable fish consumed by hake were rockfish. Heavy seasonal predation by Pacific hake on juvenile rockfish has been observed (Hobson \& Howard 1989), and Pacific hake predation on juveniles of at least 1 of the overfished rockfish species (darkblotched) has been documented (T. Buckley, Alaska Fisheries Science Center, unpubl. data). The intensity of predation also may change as a function of spatiotemporal overlap among Pacific hake and rockfish. Pacific hake diets are known to vary in time and space (e.g. Buckley \& Livingston 1997), and climate perturbations, such as El Niño or La Niña events, affect seasonal distributions of adult Pacific hake (Dorn 1995) and pelagic age- 0 rockfish (Sakuma et al. 2006). The question then becomes whether predation influences recovery rates of depleted rockfish species that are managed primarily in terms of bycatch.

In the present study, we examine the dynamics of a 2 -species fishery where the species have radically different life histories, the target species preys on juveniles of the overfished bycatch species, and the prey contribute little to predator fitness. We hypothesize that varying predation will significantly affect the time required to rebuild the bycatch species to harvestable levels, and thus reduce the benefits of precautionary bycatch management. We investigate this by modeling populations of Pacific hake (target species; predator) and rockfish (bycatch species; prey as juveniles). An added complication is that life history and population structure vary markedly among rockfish species. To understand the importance of this variability, we include models in which Pacific hake interact with 1 of 3 different rockfish species-widow, canary, or darkblotched - with distinct life-history characteristics (Table A1); our expectation is that Pacific hake predation will affect canary rockfish (the most long lived and overfished species) the most and darkblotched rockfish (which has stochastic recruitment success) the least. Although our models are founded on data, much remains unknown about Pacific hake predation on rockfish. Thus, we explore a range of hake-rockfish interaction scenarios involving different Pacific hake feeding preferences (predator selectivity), spatiotemporal overlap patterns, and fishery closures to evaluate the potential effects of contrasting sets of conditions. 


\section{METHODS}

General model structure. At a descriptive level, the model simulates changes in the SSB of the rockfish Sebastes spp. population, the biomass of juvenile rockfish, and the biomass of the Pacific hake Merluccius productus population in monthly time steps. The Pacific hake fishery inflicts fishing mortality on both populations, and the only other dynamic source of mortality is predation by Pacific hake on juvenile rockfish. The model progresses from an initial state until the rockfish population increases to $40 \%$ of unfished $\mathrm{SSB}_{\text {; }}$ the time required to do so is the rebuilding time, which we call $T_{40 \%}$.

Below, we provide the specific model structure for the Pacific hake and widow rockfish Sebastes entomelas interaction. There are several changes in model parameters or structure when canary rockfish $S$. pinniger or darkblotched rockfish $S$. crameri are the nontarget species. These changes, due to differences in rockfish life history or population structure (Table A1), are summarized in Appendix 1.

Model structure for widow rockfish and Pacific hake. The widow rockfish and Pacific hake model populations are initialized using age distributions and population sizes given in recent stock assessments for both species (Helser et al. 2004, He et al. 2005; Table A1). We refer to the abundance of Age $i$ rockfish at month $t$ as $R_{i}(t), i=0, \ldots, 20$, and let the abundance of Age $j$ Pacific hake at month $t$ be $H_{j}(t), i=2, \ldots, 15$. The oldest age classes, $R_{20}(t)$ and $H_{15}(t)$, include rockfish $\geq 20 \mathrm{yr}$ old and Pacific hake $\geq 15 \mathrm{yr}$ old, respectively. On January 1 of each year, pelagic rockfish larvae are produced in proportion to the age-specific standing rockfish stock:

$$
R_{0}(t)=\sum_{i} \phi_{i} R_{i}(t)
$$

where $\phi_{i}$ is the per capita reproduction of Age $i$ rockfish, derived from age-specific fecundities and maturity ogives of widow rockfish (Table A1), and assuming a sex ratio of 1:1. Meanwhile, Pacific hake recruits, $H_{2}(t)$, are determined by a random draw from historic estimates of Age-2 recruit classes; this is consistent with the highly variable nature of Pacific hake recruitment (Helser et al. 2004). From January through March, all rockfish (except Age-0 larvae; see below) and Pacific hake perish at their respective constant monthly rates $m_{r}$ and $m_{h}$ :

$$
\begin{array}{ll}
R_{i}(t+1)=R_{i}(t) \mathrm{e}^{-m_{r}} & i=1, \ldots, 20 \\
H_{j}(t+1)=H_{j}(t) \mathrm{e}^{-m_{h}} & j=2, \ldots, 15
\end{array}
$$

Between January 1 and April 1, pelagic rockfish larvae suffer a much greater mortality rate, $m_{l}$ (Table A1), so $R_{0}(t+1)=R_{0}(t) \mathrm{e}^{-m_{l}}$. We iteratively adjusted $m_{l}$ until our model population's rebuilding time matched the target rebuilding time in the widow rockfish rebuilding plan (He et al. 2005). After April 1, all rockfish experience $m_{r}$.

From April 1 to November 1, Pacific hake are on their northerly feeding grounds and overlap spatially with rockfish. During this time, the Pacific hake fishery targets Pacific hake and incidentally catches rockfish. Rockfish dynamics during this period are given by:

$$
\begin{gathered}
R_{i}(t+1)=R_{i}(t) \mathrm{e}^{-p_{i}(t)-m_{T}} \quad i=0 \\
R_{i}(t+1)=R_{i}(t) \mathrm{e}^{-m_{I}-F_{i}(t)} \quad i=1, \ldots, 20
\end{gathered}
$$

where $p_{i}(t)$ and $F_{i}(t)$ terms are age-specific predation and bycatch rates, respectively. We assume that only Age-0 widow rockfish are vulnerable to predation by Pacific hake, based on evidence from widow rockfish size at age (Table A1) and sizes of rockfish found in Pacific hake stomachs (T. W. Buckley unpubl. data). Although only a single predation rate $\left(p_{0}\right)$ is needed for widows, we use age-specific predation rates in Eq. (4) because multiple age classes of other rockfish species (e.g. darkblotched) are vulnerable to hake predation (see Appendix 1). We assume that Pacific hake become piscivores at Age 3 (Rexstad \& Pikitch 1986), that only $0.4 \%$ of Age- $3+$ Pacific hake eat rockfish, and, of those, $1 \%$ of their diet is rockfish (T. W. Buckley unpubl. data). Predation rates are the product of $\alpha_{i}$ (i.e. proportion body mass consumed daily by Pacific hake = $-0.000643 \times$ age +0.01207 ; Francis 1983), predator selectivity $(S)$, Pacific hake densities, and yearly and monthly stochastic effects $Y(t)$ and $Z(t)$ such that:

$$
p_{i}(t)=\alpha_{i} S Y(t) Z(t) \sum_{j=3}^{15} H_{j}(t)
$$

Adjusting $S$ changes the predation rate on widow rockfish; if Pacific hake are feeding non-selectively $(S=1)$, then $10.67 \%$ of rockfish eaten are widow rockfish, which is equal to their mean relative abundance (calculated according to Pennington 1996) in coastwide juvenile rockfish trawls conducted from 2004 to 2006 (described in Sakuma et al. 2006; data provided by Steve Ralston, Southwest Fisheries Science Center). Finally, because current estimates of rockfish mortality include hake predation at current levels, mortality rates of vulnerable rockfish age classes are adjusted by subtracting initial predation rates [e.g. $\alpha_{i} \sum_{j=3}^{15} H_{j}(0)$ for age- 0 widow rockfish] to ensure that hake predation is not double-counted.

Age-specific rockfish bycatch rates are equal to deterministic, age-specific baseline bycatch rates, $F_{i}$ and age-specific gear-selectivity coefficients, $\gamma_{i r}$ as well as stochastic effects such that:

$$
F_{i}(t)=Y(t) Z(t) F_{i} \gamma_{i} \quad i=1, \ldots, 20
$$

Pacific hake dynamics during the period from April 1 to November 1 are given by: 


$$
H_{j}(t+1)=H_{j}(t) \mathrm{e}^{-m h-G j \gamma j} \quad j=2, \ldots, 15
$$

where $G_{i}$ terms are age-specific harvest rates.

Rockfish bycatch and Pacific hake harvest for each month that the fishery is open are determined by the Baranov catch equations (Quinn \& Deriso 1999):

$$
\begin{array}{r}
\operatorname{rockfish}_{\operatorname{catch}}(t)=\frac{F_{i}(t)}{F_{i}(t)+m_{r}} R_{i}(t)\left(1-\mathrm{e}^{-m_{r}-F_{i}(t)}\right) \\
i=2, \ldots, 20
\end{array}
$$

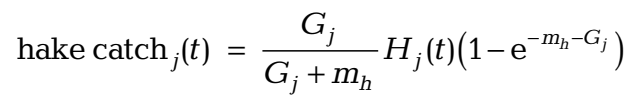

$$
j=2, \ldots, 15
$$

Rockfish catch is rescaled using the maturity ogives to determine bycatch of SSB. At the start of each fishing season, the rockfish bycatch cap is determined based on the current SSB and the maximum allowable bycatch mortality rate (Table A1). If rockfish bycatch hits or exceeds the cap prior to October, the fishery is closed $\left(F_{i}=G_{j}=0\right)$ for the remainder of the year.

We assumed that spatiotemporal overlap between Pacific hake and widow rockfish would be affected by short-term climate variability. El Niño and La Niña events occur every $\sim 5$ to $7 \mathrm{yr}$ and markedly alter the oceanography of the North American west coast. El Niño years are warmer than average and have low upwelling and poor primary production; La Niña years are cooler and experience intense upwelling and high primary production (Murphree \& Reynolds 1995). The spatial distribution of Pacific hake is affected dramatically by these anomalies (Dorn 1995). The $Y(t)$ stochastic terms in Eqs. (6) \& (7) simulate these effects. Each year, there is a 1 in 6 chance of oceanographic conditions that lead to high overlap between Pacific hake and rockfish, causing arbitrarily determined 10-fold increases in Pacific hake predation rate and adult rockfish bycatch rate $[Y(t)=10]$; a 1 in 6 chance of conditions that lead to low overlap and decrease predation and bycatch by an arbitrary factor of $10[Y(t)=0.1]$; and a 2 in 3 chance of neutral conditions [ $Y(t)=1]$. The $Z(t)$ terms in Eqs. (6) \& (7) are included to introduce small monthly variability in spatial overlap that is independent of the yearly effects. The $Z(t)$ terms are drawn each month from a lognormal distribution (median $=1$; $\mathrm{SD}=0.1$ ).

Pacific hake migrate southwards on November 1. The final 2 monthly transitions of each model year are determined using Eqs. (2) \& (3). At the end of each year, surviving fish graduate to the next age class; survivors in the eldest age classes remain in those classes.

The model is allowed to run until widow rockfish SSB reaches $40 \%$ of the estimated unfished $\mathrm{SSB}_{\text {; }}$ at that time $\left(T_{40 \%}\right)$, it is considered rebuilt. According to our initial model state, the SSB of widow rockfish is $31 \%$ of unfished (Table A1), and therefore must increase by a factor of 1.29 to be rebuilt.

Model scenarios. We modeled the trade-offs between rockfish bycatch and predation for 3 different overfished rockfish species that span a range of life histories and population structures (Table A1). Widow rockfish are our exemplar of a 'typical' rockfish life history, and often experience bycatch mortality in the Pacific hake fishery; canary rockfish are a heavily overfished, longer-living, later-maturing species, with a strong stock-recruitment relationship (Dorn 2002); and darkblotched rockfish are an overfished, longliving species with stochastic recruitment. For each species, we ran sets of 1000 simulations, varying 2 key parameters: Pacific hake selectivity and environmental variability. In each simulation, we recorded $T_{40 \%}$, and also how often the simulated fishery had to be closed prematurely because the rockfish bycatch cap was met. We ran multiple sets of 1000 scenarios, increasing $S$ from 0 (no Pacific hake predation) to 1 (neutral selectivity), and continuing to increase $S$ until $T_{40 \%}$ had doubled from the $S=1$ case.

In our models, annual variability in spatiotemporal overlap of rockfish and Pacific hake stocks drives fluctuations in bycatch and predation. To test the sensitivity of $T_{40 \%}$ to climate-driven variation in spatiotemporal overlap, we ran additional simulations in which we varied the frequency of high or low overlap years. In all cases, each year had a 2 in 3 chance of neutral climate conditions and a 1 in 3 chance of a climate anomaly. Within these constraints, we ran simulations where high-overlap years were either equally likely, twice as likely, or one-half as likely as low-overlap years. These simulations were run at neutral selectivity $(S=1)$.

Analysis of model output. For each set of simulations, we calculated median $T_{40 \%}$, interquartile ranges, and 10th and 90th percentiles. We used medians instead of means because many simulations, particularly at higher values of $S$, produced skewed distributions. Distributions of $T_{40 \%}$ for all scenarios are presented in box-and-whisker plots, and multisample median tests with Tukey-type a posteriori multiple comparisons (Zar 1984) were used to compare medians.

To analyze the correlation between the number of early fishery closures and rockfish recovery times, we calculated and compared rebuilding times for each rockfish life history and 3 values of $S$ (no predation [ $S=0]$, neutral selectivity [ $S=1]$, and the level of $S$ that doubled $T_{40 \%}$ for each species [2.25 for widow rockfish, 1.75 for canary rockfish, 4 for darkblotched rockfish; 
see 'Results']). Comparisons for a given rockfish were done by ANCOVA, where $T_{40 \%}$ was the response variable, the number of closures was the independent variable, and $S$ was the covariate. We also compared scenarios by determining the 2.5th and 97.5th percentiles of $T_{40 \%}$ as a function of the number of closures, and visually examining the amount of overlap between pairs of scenarios.

\section{RESULTS}

\section{Effects of Pacific hake selectivity for juvenile widow rockfish as prey}

Increasing selectivity by Pacific hake Merluccius productus as predators of juvenile widow rockfish Sebastes entomelas caused prolonged widow rockfish rebuilding time (Fig. 1a, Table 1). Without predation $(S=0)$, median $T_{40} \%=20 \mathrm{yr}$. Incrementally increasing to selectivity to neutral predation $(S=1)$ resulted in a median $T_{40 \%}$ of $28 \mathrm{yr}$ (i.e. the rebuilding time formally estimated
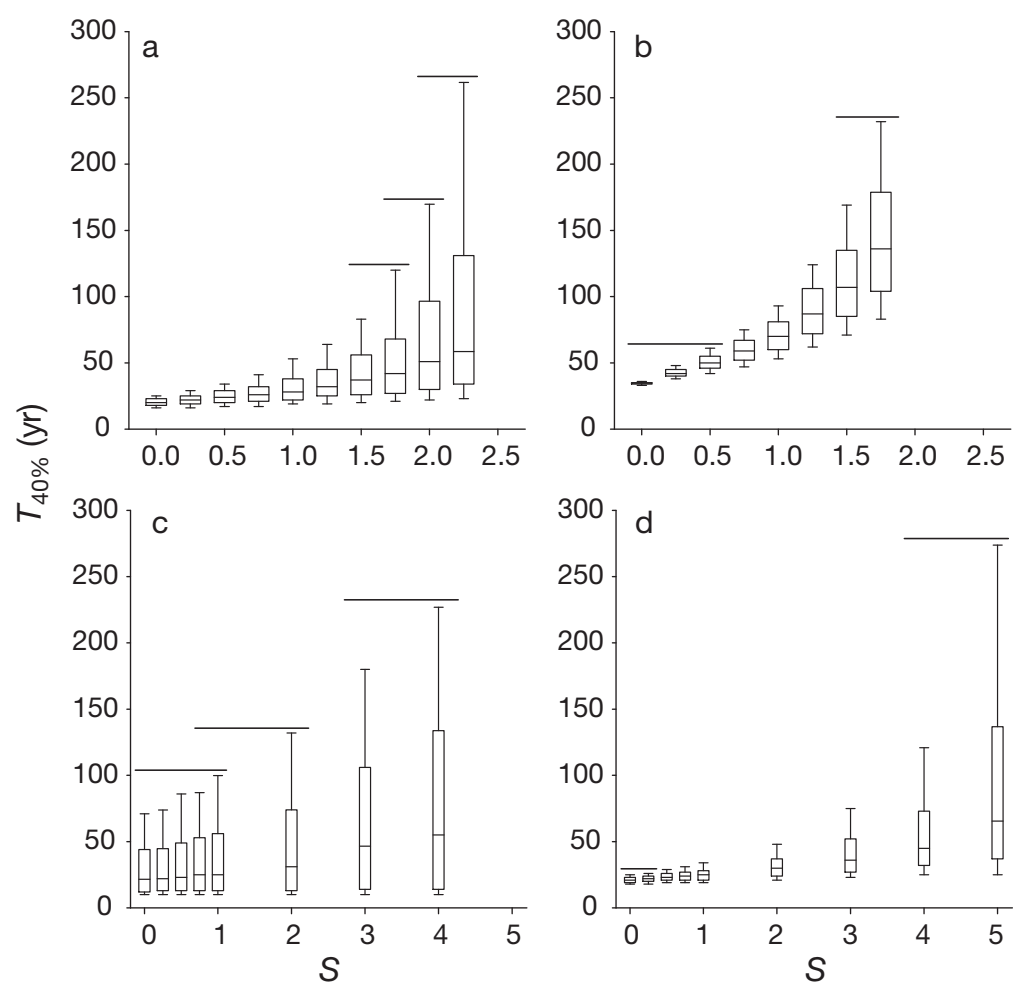

Fig. 1. Merluccius productus and Sebastes spp. Rockfish rebuilding time $\left(T_{40 \%}\right)$ as a function of selectivity $(S)$ by Pacific hake as juvenile rockfish predators. Boxes are median values, 25 th and 75 th percentiles; whiskers are 10th and 90th percentiles. Horizontal lines overlie boxes for which the medians did not differ significantly. (a) Widow rockfish $S$. entomelas, (b) canary rockfish $S$. pinniger, (c) darkblotched rockfish $S$. crameri for which stochastic recruitment is assumed and (d) darkblotched rockfish for which deterministic recruitment is assumed
Table 1. Merluccius productus and Sebastes spp. Multisample median tests for models of hake interactions with 3 rockfish species. Tests are of rebuilding times across ranges of hake predation selectivity. Results are chi-squared $\left(\chi^{2}\right)$ values, relative to critical values at $\alpha=0.05$ with $v$ degrees of freedom

\begin{tabular}{|c|c|c|c|c|}
\hline Rockfish species & $V$ & $\chi_{0.05, v}^{2}$ & $\chi^{2}$ & $\mathrm{p}$ \\
\hline Widow $S$. entomelas & 9 & 16.919 & 2869.22 & $<0.0001$ \\
\hline Canary $S$. pinniger & 7 & 14.067 & 5305.78 & $<0.0001$ \\
\hline \multicolumn{5}{|l|}{ Darkblotched $S$. crameri } \\
\hline Stochastic recruitment & 7 & 14.067 & 175.82 & $<0.0001$ \\
\hline Deterministic recruitment & 8 & 15.507 & 3626.16 & $<0.0001$ \\
\hline
\end{tabular}

by $\mathrm{He}$ et al. [2005]) and also increased variability among simulations, as shown by the larger interquartile distances (Fig. 1a). Doubling median $T_{40 \%}$ required increasing $S$ to between 2 and 2.25. That is, Pacific hake would have to eat more than twice as many widow rockfish as expected, based solely on the relative abundance of widow rockfish in the juvenile rockfish biomass pool, in order to double widow rockfish $T_{40 \%}$. Variability in $T_{40 \%}$ was much greater at these higher levels of $S$. Differences in $T_{40 \%}$ at different increments of $S$ were mostly significant (Fig. 1a), suggesting that changes in Pacific hake predation, even over a limited range, could measurably affect widow rockfish rebuilding time, if the underlying predator-prey interaction exists as hypothesized.

\section{Effects of rockfish life history and population structure}

Changing the rockfish life-history parameters from values characteristic of widow rockfish to those of canary rockfish Sebastes pinniger resulted in greater sensitivity to $S$ (Fig. 1b, Table 1). With no predation $(S=0)$, median canary rockfish $T_{40 \%}=35 \mathrm{yr}$. Neutral predation $(S=1)$ doubled median $T_{40 \%}$ to $70 \mathrm{yr}$ (i.e. the rebuilding time formally estimated by Methot [2005]), with considerably greater variability about the median. Increasing $S$ to 1.75 essentially doubled median $T_{40 \%}$ (= $136 \mathrm{yr}$ ) relative to the $S=1$ model. Median $T_{40 \%}$ values were significantly different between most of the incremental values of $S$ that we tested, and once $S>$ 0.75 , increasing $S$ by 0.25 resulted in prolonging canary rockfish median $T_{40 \%}$ by at least a decade. 
Changing the rockfish traits to those of darkblotched rockfish Sebastes crameri resulted in a more modest response to predation. At $S=0$, darkblotched rockfish median $T_{40 \%}=22 \mathrm{yr}$. At $S=1$, median $T_{40 \%}$ was $25 \mathrm{yr}$ (i.e. the rebuilding time formally estimated by Rogers [2005]), which was not statistically different from the scenarios with lower values of $S$, due in part to high variability (Fig. 1c). Darkblotched rockfish median $T_{40 \%}$ increased more slowly than in the other rockfish, as Pacific hake became more selective; $T_{40 \%}$ did not double until $S$ was between 3 and 4 . That is, the darkblotched rockfish population dynamics were relatively insensitive to Pacific hake predation unless Pacific hake preyed very preferentially on darkblotched rockfish juveniles. The variability around median $T_{40 \%}$ was far greater for darkblotched rockfish than for the other rockfish species, likely due to their stochastic reproductive success.

Two characteristics that distinguish darkblotched rockfish from the other 2 rockfish are their stochastic recruitment and their scarcity in Pacific hake diets at $S=1$ (at least an order of magnitude lower than the other species; Table A1). To distinguish between these 2 effects, we remodeled the darkblotched rockfish response to $S$, but, in this case, darkblotched recruitment was modeled deterministically, as with widow and canary rockfish (see Appendix 1). The resulting median $T_{40 \%}$ values were qualitatively comparable to the stochastic case, increasing slightly as $S$ increased from 0 to 1 and then accelerating as $S$ increased further (Fig. 1d). However, unlike the stochastic case, most of the differences at low values of $S$ were significant in the deterministic scenario. Doubling of median $T_{40 \%}$ required a greater degree of Pacific hake predation $(4<S<5)$ than in the stochastic scenarios. Variability of $T_{40 \%}$ as a function of $S$ was much lower in the deterministic darkblotched rockfish models. Overall, the deterministic and stochastic darkblotched rockfish scenarios, while distinguishable from one another, were both starkly less sensitive to $S$ than the widow rockfish scenario and the canary rockfish scenario.

\section{Effects of changing spatiotemporal overlap between Pacific hake and rockfish}

Rockfish rebuilding time responded to changes in the degree of spatiotemporal overlap between rockfish and Pacific hake, and the magnitude of response varied among the 3 rockfish species (Fig. 2, Table 2). For each rockfish, we present model outputs for $S=0$ (no predation) and $S=1$ (neutral selectivity); at $S=1$, we examine cases with normal spatiotemporal overlap, higher-than-normal overlap, and lower-than-normal overlap.

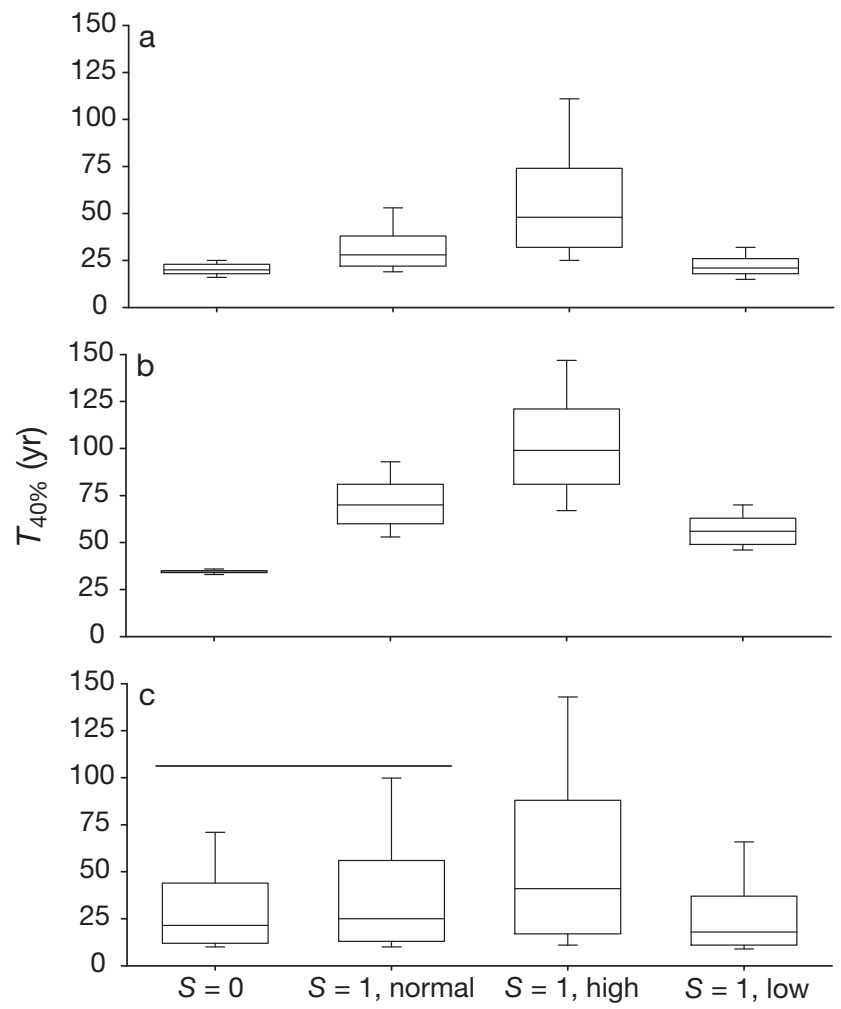

Fig. 2. Merluccius productus and Sebastes spp. Rockfish rebuilding time $\left(T_{40}\right)$ as a function of Pacific hake selectivity $(S)$ and spatiotemporal overlap between rockfish and Pacific hake. Boxes and whiskers are as in Fig. 1. Normal: normal spatiotemporal overlap; high: higher than normal overlap; low: lower than normal overlap. Horizontal lines overlie boxes for which the medians did not differ significantly: (a) widow rockfish $S$. entomelas, (b) canary rockfish $S$. pinniger and (c) darkblotched rockfish $S$. crameri

Table 2. Merluccius productus and Sebastes spp. Multisample median tests for models of hake interactions with 3 rockfish species. Tests are of rebuilding times across 4 scenarios of hake predation and climate-driven spatiotemporal overlap. Results are chi-squared $\left(\chi^{2}\right)$ values, relative to critical values at $\alpha=0.05$ with $v$ degrees of freedom

\begin{tabular}{|lccccc|}
\hline Rockfish species & $v$ & $\chi_{0.05, v}^{2}$ & \multicolumn{1}{c|}{$\chi^{2}$} & $\mathrm{p}$ \\
\hline Widow S. entomelas & 3 & 7.815 & 1491.34 & $<0.0001$ \\
Canary S. pinniger & 3 & 7.815 & 2131.52 & $<0.0001$ \\
Darkblotched S. crameri & 3 & 7.815 & 78.45 & $<0.0001$ \\
(stochastic recruitment) & & & & \\
\hline
\end{tabular}

For widow rockfish, median $T_{40 \%}$ at $S=0$ and $S=1$ were 20 and $28 \mathrm{yr}$, respectively, when the probabilities of higher-than-normal and lower-than-normal overlap were identical (1/6) (Fig. 2a). When the probability of high overlap was twice that of low overlap and $S=1$, median $T_{40 \%}$ increased to $48 \mathrm{yr}$, and the variability 
around the median increased sharply. In contrast, when low overlap was twice as probable and $S=1$, median $T_{40 \%}$ was $21 \mathrm{yr}$, which was only slightly greater than the baseline scenario with $S=0$. In other words, low spatiotemporal overlap nearly offset the full predatory effect of Pacific hake. All pairwise differences of medians were significant (all p < 0.001).

For canary rockfish, median $T_{40 \%}$ at $S=0$ and $S=1$ were 35 and $70 \mathrm{yr}$, respectively, under baseline overlap conditions (Fig. 2b). As with widow rockfish, $T_{40 \%}$ increased when high overlap was twice as probable as low overlap and $S=1$, although the increase was more extreme in absolute terms (median $T_{40 \%}=99 \mathrm{yr}$ ). When low overlap was twice as probable and $S=1$, median $T_{40 \%}$ decreased to $56 \mathrm{yr}$, which was still greater than the baseline median at $S=0$; thus, unlike widow rockfish, low overlap did not offset the Pacific hake predation effect. Again, all pairwise comparisons yielded significant differences (all $\mathrm{p}<0.001$ ).

Darkblotched rockfish outputs were characterized by high variability (Fig. 2c), mainly due to the stochastic nature of their reproduction. Median $T_{40} \%$ values at $S=0$ and $S=1$ with a normal overlap regime were 22 and 25 years, respectively. When $S=1$ and overlap was high, median $T_{40 \%}$ increased to $41 \mathrm{yr}_{\text {; }}$ variability around the median was high and overlapped to some extent with the other scenarios. At $S=1$ and relatively low overlap, the median $T_{40 \%}$ was $18 \mathrm{yr}$, and the range of outcomes overlapped considerably with the $S=$ 0 condition, again implying that lower-than-normal overlap essentially negated the predatory effect of Pacific hake. There was no statistical difference between the scenarios with $S=0$ and $S=1$ plus low overlap ( $p>0.1)$. All other pairwise comparisons indicated significant differences among medians.

\section{Correlation with early fishery closures triggered by rockfish bycatch quotas}

Early closure of the Pacific hake fishery was associated with increased rebuilding time for each rockfish. In models with no Pacific hake predation $(S=0), T_{40 \%}$ increased as a linear function of the number of early fishery closures (Fig. 3). This increase occurred simply because frequent fishery closures are indicative of higher rockfish bycatch mortality and, hence, slower population growth.

Increasing $S$ revealed an interaction between Pacific hake predation and fishery closures that was substantial for widow and canary rockfish, but weak for darkblotched rockfish when stochastic reproduction was assumed. Increasing $S$ for widow rockfish to neutral selectivity and then to 2.25 caused the slope of $T_{40 \%}$ as a function of fishery closures to increase (Fig. 3a;

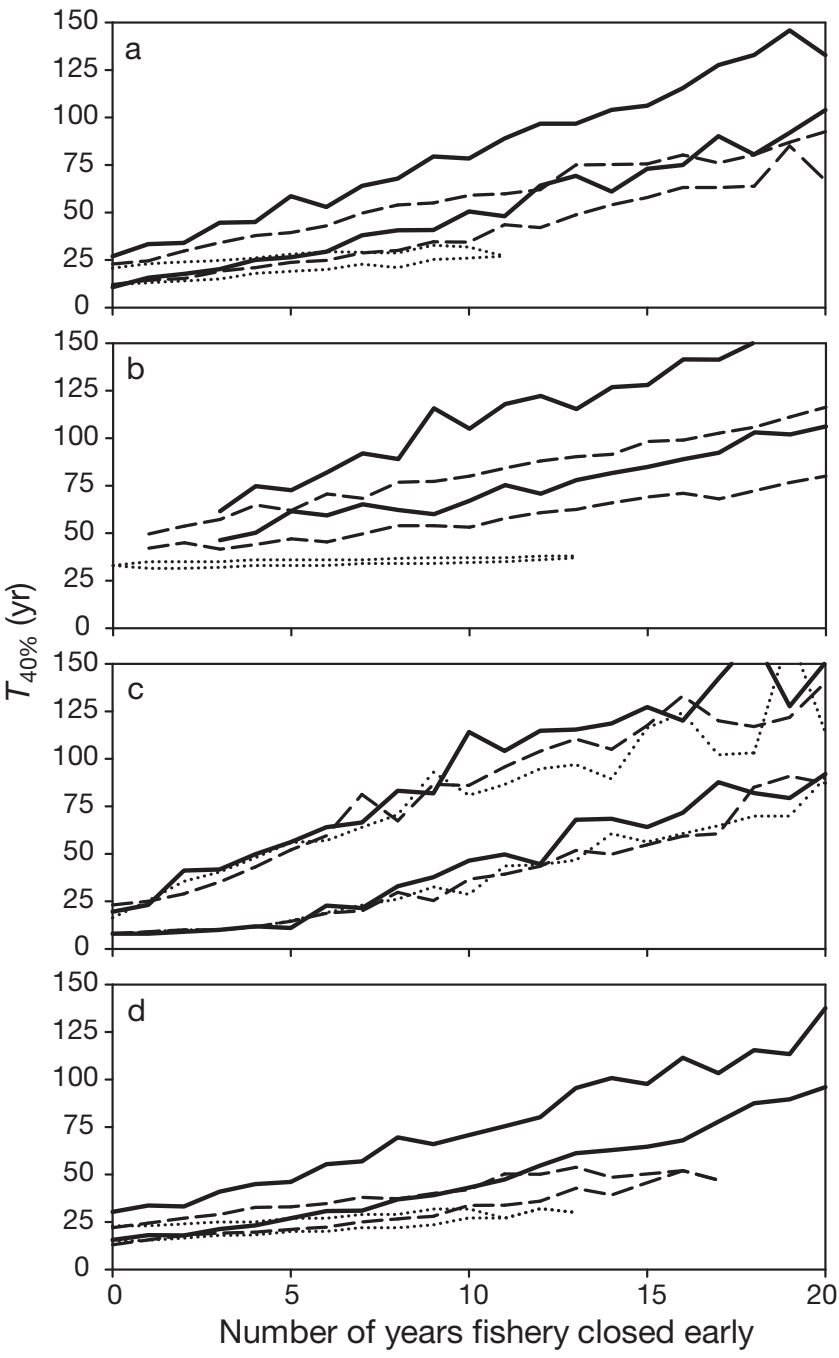

Fig. 3. Merluccius productus and Sebastes spp. Rockfish rebuilding times $\left(T_{40 \%}\right)$ as a function of early fishery closures and Pacific hake selectivity $(S)$. Lines indicate the 2.5th and 97.5th percentiles of values observed at each level of early fishery closure. Dotted lines: percentiles when $S=0$; dashed lines: percentiles when $S=1$; solid lines: (a) percentiles when $S=2.25$, (b) 1.75, or (c,d) 4. (a) Widow rockfish $S$. entomelas, (b) canary rockfish $S$. pinniger, (c) darkblotched rockfish $S$. crameri with stochastic recruitment and (d) darkblotched rockfish with deterministic recruitment. Note: in all plots, data extend beyond the range displayed but are not shown in order to improve visual clarity near the origins of the axes

slope $_{S=0}=1.32 ;$ slope $_{S=1}=3.31 ;$ slope $_{S=2.25}=5.18$ ). Although the 3 levels of $S$ produced distinct slopes (Table 3; Tukey's pairwise comparisons, all $\mathrm{p}<0.001$ ), there was some overlap across the 3 values of $S$ when the number of closures was $<4$. Beyond this level, the 3 sets of outcomes diverged (particularly $S=0$ vs. $S=$ 2.25). Thus, the interaction of predation intensity with the frequency of closures was equivocal if the number of closures was kept low through effective bycatch management. Canary rockfish experienced a some- 
Table 3. Merluccius productus and Sebastes spp. ANCOVA of estimated rockfish $T_{40 \%}$ as a function of hake predatory selectivity $(S)$ and the number of early fishery closures caused by adult rockfish bycatch

\begin{tabular}{|lcccc|}
\hline Species & $V$ & MS & $F$ & $p$ \\
Source & & & & \\
\hline Widow S. entomelas & & & & \\
$S$ & 2 & 139.38 & 2.014 & 0.134 \\
No. of closures & 1 & 318426 & 4600 & $<0.001$ \\
$S \times$ closures & 2 & 60681 & 877 & $<0.001$ \\
Error & 2994 & 61.53 & & \\
Canary S. pinniger & & & & \\
$S$ & 2 & 2652 & 23.63 & $<0.001$ \\
No. of closures & 1 & 227288 & 2025 & $<0.001$ \\
$S \times$ closures & 2 & 80805 & 720 & $<0.001$ \\
Error & 2994 & 112.26 & & \\
Darkblotched S. crameri (stochastic) & & \\
$S$ & 2 & 394.23 & 1.82 & 0.162 \\
No. of closures & 1 & 5099250 & 23524 & $<0.001$ \\
$S \times$ closures & 2 & 16058 & 74.08 & $<0.001$ \\
Error & 2994 & 216.76 & & \\
Darkblotched S. crameri (deterministic) & & \\
$S$ & 2 & 1864 & 59.37 & $<0.001$ \\
No. of closures & 1 & 150362 & 4789 & $<0.001$ \\
$S \times$ closures & 2 & 51337 & 1635 & $<0.001$ \\
Error & 2994 & 31.40 & & \\
\hline
\end{tabular}

what stronger interaction between the number of closures and predation intensity as $S$ was increased from 0 to 1 and then to 1.75 (Fig. 3b). The slopes of $T_{40 \%}$ versus fishery closures increased as $S$ increased (slope $_{S=0}=0.28 ;$ slope $_{S=1}=2.64 ;$ slope $\left._{S=1.75}=4.53\right)$, and the changes were significant (Table 3 ; Tukey's pairwise comparisons, all $\mathrm{p}<0.001$ ). Overlap between the $S=1$ and $S=1.75$ scenarios was modest; neither of these scenarios produced overlap with the $S=0$ scenario. Additionally, at $S=1$ or $S=1.75$, the minimum number of closures was $>0$, which suggests that heavy Pacific hake predation on juveniles greatly increases the likelihood that canary rockfish will experience unacceptably high bycatch at least once during their rebuilding period.

In contrast, darkblotched rockfish exhibited a much weaker interaction between the number of fishery closures and Pacific hake predation. Because darkblotched rockfish were relatively insensitive to Pacific hake predation, we increased $S$ from 0 to 1 and then to 4 to examine the interaction. Overlap of model outcomes at different values of $S$ was considerable, even at large numbers of closures (Fig. 3c). Additionally, the slopes of $T_{40 \%}$ versus total number of fishery closures changed only slightly across values of $S$ (slope $_{S=0}=$ $4.84{ }_{i}$ slope $_{S=1}=5.19 ;$ slope $_{S=4}=5.69$ ). Although these changes were statistically significant (Table 3; Tukey's pairwise comparisons, all $\mathrm{p}<0.001$ ), the degree of model overlap shown in Fig. 3c may make these sce- narios indistinguishable in a management context (i.e. at an acceptably low frequency of fishery closures). The stochastic nature of darkblotched rockfish yearclass success apparently caused this weaker interaction: when the darkblotched rockfish reproduction was modeled deterministically (see Appendix 1), the slope of $T_{40 \%}$ versus total number of fishery closures clearly increased as $S$ was increased slope $_{S=0}=0.97$; slope $_{S=1}=1.96 ;$ slope $_{S=4}=4.71$ ). The differences in slope were significant (Table 3 ), and the model outcomes at different levels of $S$ clearly diverged as the number of closures approached 10 (Fig. 3d).

\section{DISCUSSION}

Rebuilding certain depleted fish stocks will entail a more comprehensive approach than traditional management based on single species models. NOAA Fisheries has specifically identified bycatch, indirect effects of fishing, and interactions between biological and physical ecosystem components as research priorities underlying an ecosystem approach to fisheries management (Sissenwine \& Murawski 2004). Scientists and managers are addressing each of these issues as related to conservation of Pacific rockfish Sebastes spp. Recent examples include modified trawl gear that reduces bycatch of some rockfish yet maintains or increases flatfish catch (King et al. 2004), the linking of bocaccio rockfish Sebastes paucispinis recruitment to oceanographic conditions (Tolimieri \& Levin 2005), and a theoretical study suggesting that lingcod Ophiodon elongatus predation on juvenile bocaccio can reduce the efficacy of nearshore marine protected areas designed to rebuild bocaccio stocks (Mangel \& Levin 2005).

Our study considers hypothetical trophic and fishery interactions between one of the ecosystem's most abundant species, Pacific hake Merluccius productus, and 3 overfished rockfish that are bycatch in the Pacific hake fishery. We also add a proxy for a physical factor, the stochastic environmental variable that affects spatiotemporal overlap between the species. Although our models clearly simplify or arbitrarily force many ecological processes, fishery practices, and management actions, our intention was to present a first look at these interactions, gauge their importance, and provide a theoretical basis for more sophisticated models, particularly future generations of stock assessment models that include dynamic species interactions.

Despite the minor occurrence of juvenile rockfish in Pacific hake diets, varying Pacific hake predation caused a response in rockfish population recovery rates. Increasing Pacific hake selectivity prolonged 
median rebuilding times in all 3 rockfish species (Fig. 1). In management terms, the response by canary rockfish Sebastes pinniger was perhaps the most noteworthy: fixing $S$ at \pm 0.25 around neutral selectivity changed the median $T_{40 \%}$ of canary rockfish by a decade or more, which is long in both relative and absolute terms compared to 2 to $4 \mathrm{yr}$ for widow $S$. entomelas or darkblotched rockfish $S$. crameri. Moreover, in 2 of the 3 species (or all 3, if darkblotched rockfish year-class strength is deterministically related to stock structure rather than stochastic), there was a pronounced interaction between predation intensity on juvenile rockfish and bycatch intensity on adults (Fig. 3). The basis for this interaction is partly in the structure of the model: in the randomly determined years in which spatiotemporal overlap is high, order of magnitude increases automatically occur in both adult bycatch and juvenile predation; thus, fishery closures are likely to happen in years when predation is also very high, which would only be further exacerbated by increasing $S$. The other mechanism underlying the interaction is more ecological in nature and is conceptually similar to a trophic cascade (Pace et al. 1999): an early fishery closure results in lower fishing mortality on Pacific hake, which, in turn, means greaterthan-expected Pacific hake biomass and increased predation on juvenile rockfish.

Another effect of increasing $S$ was to increase the variability of $T_{40 \%}$ in each of the 3 rockfish species. The increase in variability is likely related to the high variability of Pacific hake biomass, due to stochastic Pacific hake year-class strength (Helser et al. 2004). Consequently, as Pacific hake became a more important source of juvenile rockfish mortality through increasing $S$, rockfish were increasingly linked to the high variability of Pacific hake biomass. Thus, including a dynamic species interaction may add uncertainty to the rebuilding time and change the probability of meeting rebuilding goals based on single-species assumptions.

While predation by Pacific hake on rockfish juveniles was capable of slowing rockfish population growth rates, bycatch of adult rockfish in the Pacific hake fishery remained a critical component of rockfish recovery. This was especially true for widow and darkblotched rockfish, as illustrated in Fig. 2: in the scenarios where lower-than-normal spatiotemporal overlap occurred and predation selectivity was neutral, widow and darkblotched rockfish rebuilding times were shorter than the case in which overlap was normal but predation was removed $(S=0)$. Thus, precautionary fishery practices that minimize bycatch (particularly in years where high spatiotemporal overlap is expected) can potentially compensate for hake predation on rockfish juveniles in our model system; this is advanta- geous because bycatch is easier to monitor and manage than a predator-prey interaction. In the case of canary rockfish, the lower-than-expected overlap scenario depicted in Fig. 2b only partly offset the effects of predation. That finding underscores the notion that some species may be more susceptible to predation than others, and therefore require more stringent compensatory measures (e.g. further effort to reduce bycatch).

Overall, canary rockfish appeared to respond most strongly to changes in Pacific hake predation, while darkblotched rockfish were the least responsive. Canary rockfish $T_{40 \%}$ was the most responsive to changes in $S$, in both proportional and absolute terms, and Pacific hake predation was not fully offset by low spatiotemporal overlap. In contrast, darkblotched rockfish $T_{40 \%}$ responded weakly at reasonable levels of $S$ and did not double until $S$ was $\approx 4$, a seemingly unrealistic level of preference by an opportunistic predator. The mechanisms that underlie differences in rockfish responses are, in part, the same mechanisms that underlie differences in rockfish population biology (maturation rates, natural mortality, fecundity, agespecific vulnerability to fishing gear, etc.; Table A1). Canary rockfish may have been proportionally more responsive in our models because females mature 4 or 5 yr later, on average, than those of the other 2 species (Wyllie-Echeverria 1987) and because they have relatively low natural mortality (Table A1), particularly prior to maturation (Appendix 1; Methot 2005), both traits that make them more susceptible to added mortality sources (Parker et al. 2000). We had hypothesized that darkblotched rockfish recovery times would be less sensitive to Pacific hake predation because their stochastic reproductive success would serve as a disconnect between the size of a given year class and Pacific hake impacts on previous year classes. However, the similarity between median $T_{40 \%}$ of darkblotched rockfish that were modeled with both stochastic and deterministic reproductive success (Fig. 1c,d) implies that another factor was responsible. One key factor was that the frequency of juvenile darkblotched rockfish in Pacific hake diets was an order of magnitude lower than that of the other 2 species (Table A1), such that Pacific hake predation represented a much lower proportion of total mortality.

Our models employed a Type I functional response by Pacific hake, where the rate of consumption is linearly proportional to rockfish abundance, rather than a Type III functional response, where the relationship is sigmoid, as may be most appropriate for opportunist predators that encounter patches of prey. That pattern of prey encounter and consumption has been observed in Pacific hake (e.g. Tanasichuk et al. 1991). We chose the Type I form because we lacked 
empirical data to describe a higher order functional response. Had we used a Type III model, we might have seen even greater consequences of predation for rockfish. By making periods of high overlap even worse for rockfish, a Type III functional response would amplify the effect of environmental variability on rockfish losses due to Pacific hake predation. Also, a Type III functional response implies that per capita Pacific hake predation on rockfish will accelerate as rockfish stocks are rebuilt and rockfish become more abundant over time. In this case, we might expect the rate of rockfish recovery to decelerate as rockfish approach $B_{\mathrm{MSY}}$, although it is unknown if this effect would drive appreciable increases in rebuilding time; for example, Rindorf \& Gislason (2005) determined parameters for Type II and Type III functional responses for another gadoid, whiting Merlangus merlangus, on several prey species. They concluded that whiting were only capable of regulating the population size of clupeid prey when clupeid density was low to moderate.

Although our models produced predation and fishery effects that clearly linked rockfish recovery to Pacific hake, we must highlight 2 caveats that underlie future research in this area: (1) we know little about actual rates of predation on overfished rockfish species; (2) how we interpret model output depends on our assumptions about the spatial scale of species interactions. Concerning actual predation rates, the range of outcomes in the scenarios indicates how sensitive our model is to assumptions of baseline per capita consumption and selectivity. There are 7 Pacific coast rockfish species that have been declared overfished: the 3 species considered here plus bocaccio, yelloweye Sebastes ruberrimus, Pacific ocean perch S. alutus, and cowcod $S$. levis. If recovery of these species is, in fact, as sensitive to trophic interactions as is implied here, then it behooves us to focus research on predatory interactions that affect overfished species, particularly if strong interactions are suspected. Such interactions might involve abundant, generalist predators such as Pacific hake or Pacific salmon Oncorhynchus spp. (Mills et al. 2007), predators such as seabirds that are less abundant but have very high energy demands and are known to feed on overfished rockfish juveniles (Mills et al. 2007), or large piscivores such as lingcod that share common habitats with and can exploit multiple age groups of rockfish (Mangel \& Levin 2005). Studying these interactions properly (e.g. measuring age-specific predator diets, describing functional responses, determining the influence of environmental variability) will certainly require extensive field research and modeling (e.g. Rindorf \& Gislason 2005). However, such research will help to determine which rockfish stock assessments and recovery plans would be improved by adding a dynamic species interaction component, and will also determine which class of predators outlined above is most important as a source of rockfish mortality.

Concerning the spatial scale of the interaction, our model was done at the scale of the west coast of the United States, encompassing the widow, canary, and darkblotched rockfish populations overseen by United States federal management. At that scale, Pacific hake predation was capable of slowing recovery if selectivity was greater than neutral. However, if patchiness in juvenile rockfish distribution is high (see Sakuma et al. 2006), and Pacific hake occasionally find and heavily exploit those patches (as with a Type III functional response), then local depletion of juveniles may occur. How localized juvenile predation episodes affect the rockfish population at the local or coastal scale depends on a suite of factors, including recruitment dynamics, species-specific dispersal rates and distances, and the intensity of other mortality sources, including fishing. How management of overfished rockfish is affected by local depletions thus depends on the spatial scales at which decisions are made and implemented. How the scaling of predator functional responses compares to the scaling of management decisions has yet to be tested.

In conclusion, an ecosystem-based approach to fisheries management requires that we consider dynamic ecological interactions, such as predation, in recovery plans for depleted species (Mangel \& Levin 2005). In the case of the overfished rockfish described here, the abundant Pacific hake is a species that may induce a strong predatory effect, resulting in prolonged or more uncertain target rebuilding times. To the extent that our models reasonably capture hake-rockfish interactions, changes in Pacific hake abundance or predatory selectivity at short or long time scales are capable of affecting the magnitude and variability of some rockfish rebuilding times, although our results also imply that responsible management actions or fishery practices that control bycatch can compensate for predation effects. These outcomes argue for careful evaluation of predator-prey interactions that impact overfished rockfish species, both through empirical study and through models that more realistically capture dynamics such as predator-prey functional responses or spatiotemporal overlap between predators and multiple rockfish life-history stages.

Acknowledgements. T. Buckley and S. Ralston kindly provided data and valuable discussion that greatly improved this work. We also thank P. Levin, D. Aday, V. Agostini, M. E. Clarke, G. Fleischer, X. He, E. Holmes, I. Kaplan, P. Kareiva, N. Tolimieri, R. Zabel, and 2 anonymous reviewers for helpful comments and suggestions. 


\section{LITERATURE CITED}

Buckley TW, Livingston PA (1997) Geographic variation in the diet of Pacific hake, with a note on cannibalism. CCOFI Rep 38:53-62

DeMaster DP, Fowler CW, Perry SL, Richlen MF (2001) Predation and competition: the impact of fisheries on marinemammal populations over the next one hundred years. J Mammal 82:641-651

Dorn MW (1995) The effects of age composition and oceanographic conditions on the annual migration of Pacific whiting Merluccius productus. CCOFI Rep 36:97-105

Dorn MW (2002) Advice on west coast rockfish harvest rates from Bayesian-meta-analysis of stock-recruitment relationships. N Am J Fish Manag 22:280-300

Francis RC (1983) Population and trophic dynamics of Pacific hake (Merluccius productus). Can J Fish Aquat Sci 40: 1925-1943

Gotshall DW (1969) Stomach contents of Pacific hake and arrowtooth flounder from northern California. Calif Fish Game 55:75-82

Hall SJ (1999) The effects of fishing on marine ecosystems and communities. Blackwell, Oxford

Harrington JM, Myers RA, Rosenberg AA (2005) Wasted fishery resources: discarded by-catch in the USA. Fish Fish 6: 350-361

He X, Punt A, MacCall AD, Ralston S (2005) Rebuilding analysis for widow rockfish in 2005. Pacific Fishery Management Council, Portland, OR

Helser TE, Methot RD, Fleischer GW (2004) Stock assessment of Pacific hake (whiting) in U.S. and Canadian waters in 2003. Pacific Fishery Management Council, Portland, OR

Hilborn R (2004) Ecosystem-based fisheries management: The carrot or the stick? Mar Ecol Prog Ser 274:275-278

Hobson ES, Howard DF (1989) Mass strandings of juvenile shortbelly rockfish and Pacific hake along the coast of northern California. Calif Fish Game 74:169-183

Jennings SJ, Kaiser MJ, Reynolds JD (2001) Marine fisheries ecology. Blackwell, Oxford

Kelleher K (2005) Discards in the world's marine fisheries: an update. FAO Fish Tech Pap 470

King SE, Hannah RW, Parker SJ, Matteson KM, Berkeley SA (2004) Protecting rockfish through gear design: development of a selective flatfish trawl for the U.S. west coast bottom trawl fishery. Can J Fish Aquat Sci 61:487-496

Livingston PA (1983) Food habits of Pacific whiting, Merluccius productus, off the west coast of North America, 1967 and 1980. Fish Bull (Wash DC) 81:629-636

Mangel M, Levin PS (2005) Regime shifts, phase shifts and paradigm shifts: making community ecology the basic science for fisheries. Philos Trans R Soc Lond B 360:95-105

Methot RD (2005) Updated rebuilding analysis for canary rockfish based on stock assessment in 2005. Pacific Fishery Management Council, Portland, OR

Methot RD, Stewart IJ (2005) Status of the U.S. canary rockfish resource in 2005. Pacific Fishery Management Council, Portland, OR

Mills KL, Laidig T, Ralston S, Sydeman WJ (2007) Diets of top predators indicate pelagic juvenile rockfish (Sebastes spp.) abundance in the California Current system. Fish Oceanogr 16:273-283

Murphree T, Reynolds C (1995) El Niño and La Niña effects on the Northeast Pacific: the 1991-1993 and 1988-1989 events. CCOFI Rep 36:45-56
NMFS (National Marine Fisheries Service) (1999) Ecosystembased fishery management: a report to Congress by the Ecosystem Principles Advisory Panel. US Dept Commerce, Washington, DC

NRC (National Research Council) (1999) Sustaining marine fisheries. National Academy Press, Washington, DC

Outram DN, Haegle C (1972) Food of Pacific hake (Merluccius productus) on an offshore bank southwest of Vancouver Island, British Columbia. J Fish Res Board Can 29: 1792-1795

Pace ML, Cole JJ, Carpenter SR, Kitchell JF (1999) Trophic cascades revealed in diverse ecosystems. Trends Ecol Evol $14: 483-488$

> Parker SJ, Berkeley SA, Golden JT, Gunderson DR and others (2000) Management of Pacific rockfish. Fisheries 25:22-29

Pennington M (1996) Estimating the mean and variance from highly skewed marine data. Fish Bull (Wash DC) 94: 498-505

PFMC (Pacific Fishery Management Council) (2003) Acceptable biological catch and optimum yield specification and management measures for the 2004 Pacific Coast groundfish fishery. Pacific Fishery Management Council, Portland, OR

PFMC (2004) Acceptable biological catch and optimum yield specification and management measures for the 20052006 Pacific coast groundfish fishery. Pacific Fishery Management Council, Portland, OR

Quinn TJ II, Deriso RB (1999) Quantitative fish dynamics. Oxford University Press, New York

Rexstad EA, Pikitch EK (1986) Stomach contents and food consumption estimates of Pacific hake, Merluccius productus. Fish Bull (Wash DC) 84:947-956

Rindorf A, Gislason H (2005) Functional and aggregative response of North Sea whiting. J Exp Mar Biol Ecol 324: $1-19$

Rogers JB (2005) Update of darkblotched rockfish (Sebastes crameri) rebuilding analysis. Pacific Fishery Management Council, Portland, OR

Sakuma KM, Ralston S, Wespestad VG (2006) Interannual and spatial variation in the distribution of young-of-theyear rockfish (Sebastes spp.): expanding and coordinating a survey sampling frame. CCOFI Rep 47:127-139

Sissenwine M, Murawski S (2004) Moving beyond 'intelligent tinkering': advancing an ecosystem approach to fisheries. Mar Ecol Prog Ser 274:291-295

Tanasichuk RW, Ware DM, Shaw W, McFarlane GW (1991) Variations in diet, daily ration, and feeding periodicity of Pacific hake (Merluccius productus) and spiny dogfish (Squalus acanthias) off the lower west coast of Vancouver Island. Can J Fish Aquat Sci 48:2118-2128

Tasker ML, Camphuysen CJ, Cooper J, Garthe S, Montevecchi WA, Babler SJM (2000) The impacts of fishing on marine birds. ICES J Mar Sci 57:531-547

> Tolimieri N, Levin PS (2005) Fishing-climate interactions and the recovery of an overfished rockfish. Ecol Appl 15: $458-468$

Williams EH, Ralston S, MacCall AD, Woodbury D, Pearson DE (2000) Status of the widow rockfish resource in Y2K. Pacific Fishery Management Council, Portland, OR

Wyllie-Echeverria T (1987) Thirty-four species of California rockfishes: maturity and seasonality of reproduction. Fish Bull (Wash DC) 85:229-250

Zar JH (1984) Biostatistical analysis, 2nd edn. Prentice Hall, Englewood Cliffs, NJ 
Appendix 1. In 'Methods', the structure of the model was expressed in detail for Pacific hake Merluccius productus and widow rockfish Sebastes entomelas. Here, we describe model changes for the other 2 rockfish species

Model structure for canary rockfish and Pacific hake. The canary rockfish/Pacific hake model is similar to the widow rockfish/Pacific hake model described in 'Methods', but several parameters have been changed to reflect canary rockfish biology and population structure. Canary rockfish are modeled to age $25+$, and their life-history parameters, abundance, allowable bycatch rates and gear selectivity differ from those of widow rockfish (Table A1). Monthly $m_{r}=$ 0.005 for age classes $\leq 5$ (except larvae; see below), after which it increases linearly to 0.0075 by Age 13, reflecting an increase in natural mortality of females (Methot 2005). Canary rockfish $m_{l}$ was adjusted iteratively until median $T_{40 \%}$ (at $S=1$ ) was equal to the target rebuilding time in the rebuilding plan (Methot 2005). After April 1, post-larval fish follow the age-specific $m_{r}$ pattern described above. At $S=1$, the occurrence of canary rockfish in Pacific hake diet is equal to their relative abundance in the 2004 to 2006 juvenile rockfish surveys (S. Ralston unpubl. data). Only Age-0 canary rockfish are vulnerable to Pacific hake predation, based on canary rockfish size-at-age and observed rockfish sizes in Pacific hake stomachs. Model runs concluded when $\mathrm{SSB}=40 \%$ of unfished biomass, an increase of 4.26 -fold over current SSB (9.4\% of unfished).

Model structure for darkblotched rockfish and Pacific hake. The darkblotched rockfish/Pacific hake model is similar to the other models, with parameters adjusted to reflect darkblotched rockfish life history and population structure (but see below for scenarios with deterministic recruitment). Darkblotched rockfish are modeled to age $40+$, and their abundance, life-history parameters, allowable bycatch rates, gear selectivity, and target rebuilding times (Table A1) generally were derived from Rogers (2005). Monthly $m_{r}$ was slightly greater than the value of 0.00583 used by Rogers (2005); we adjusted $m_{r}$ iteratively until $T_{40 \%}$ (at $S=1$ ) matched the target rebuilding time in the rebuilding plan. To generate stochastic recruitment of new individuals to the population, the number of postlarval Age-0 juveniles that enter on April 1 of each year was determined by randomly drawing an Age-0 population estimate from a time series (1982 to 2003; Rogers 2005). We assumed that Age- 0 and -1 darkblotched rockfish are vulnerable to Pacific hake predation, based on size-at-age calculations and observed sizes of rockfish in Pacific hake stomachs, and that the number eaten from each age class is directly proportional to their abundance. The occurrence of darkblotched rockfish in Pacific hake diet at $S=1$ is assumed to equal their relative abundance in the 2004 to 2006 juvenile rockfish surveys (S. Ralston unpubl. data). Model runs conclude when SSB $=40 \%$ of unfished biomass, an increase of 2.39 -fold over the initial SSB ( $16.7 \%$ of unfished).

In cases where recruitment into the population was deterministic (see 'Results'), we used the same model structure as with widow rockfish, but with the parameters in Table A1 (including the fecundity and $m_{l}$ estimates), such that the number of larvae was based on the structure of the spawning stock. Larval mortality $m_{l}$ (January 1 to April 1) was adjusted until median $T_{40 \%}$ (at $S=1$ ) matched the target rebuilding time in the rebuilding plan (Rogers 2005). After April 1, post-larval fish experience $m_{r}$. All other functions are as described in the preceding paragraph.

Table A1. Merluccius productus and Sebastes spp. Parameter values for widow rockfish $S$. entomelas, canary rockfish $S$. pinniger, darkblotched rockfish $S$. crameri, and Pacific hake in the rockfish-hake interaction models. 'See ref.' indicates that the parameter is determined from a time series or an equation provided in the references: ${ }^{\mathrm{a}} \mathrm{He}$ et al. (2005), ' $\mathrm{Methot}(2005)$,

${ }^{\mathrm{c}}$ Rogers (2005), ${ }^{\mathrm{d}}$ Helser et al. (2004), ${ }^{\mathrm{e}}$ Williams et al. (2000), ${ }^{\mathrm{f}}$ Methot \& Stewart (2005), and ${ }^{9}$ Wyllie-Echeverria (1987)

\begin{tabular}{|c|c|c|c|c|}
\hline Parameter & Widow & Canary & Darkblotched & Hake \\
\hline \multicolumn{5}{|l|}{ Life history } \\
\hline Initial age distribution & See ref. ${ }^{a}$ & See ref. ${ }^{b}$ & See ref. ${ }^{c}$ & See ref. ${ }^{\mathrm{d}}$ \\
\hline von Bertalanffy $F_{\text {inf }}(\mathrm{cm})$ & $50.54^{\mathrm{e}}$ & $58.90^{\mathrm{f}}$ & $42.94^{\mathrm{c}}$ & n.a. \\
\hline von Bertalanffy $k$ & $0.140^{\mathrm{e}}$ & $0.146^{\mathrm{f}}$ & $0.201^{\mathrm{c}}$ & n.a. \\
\hline von Bertalanffy $t_{0}(\mathrm{yr})$ & $-2.68^{\mathrm{e}}$ & $-1.01^{\mathrm{f}}$ & $-0.1036^{\mathrm{c}}$ & n.a. \\
\hline FL-W $a^{\mp}$ & $0.00545^{\mathrm{e}}$ & $0.0155^{\mathrm{f}}$ & $0.021^{\mathrm{c}}$ & n.a. \\
\hline FL-W $b^{\mp}$ & $3.288^{\mathrm{e}}$ & $3.030^{\mathrm{f}}$ & $2.961^{\mathrm{c}}$ & n.a. \\
\hline Weight at age $a^{\mathrm{qx}}$ & n.a. & n.a. & n.a. & $1191.5^{\mathrm{d}}$ \\
\hline Weight at age $b^{4 t}$ & n.a. & n.a. & n.a. & $0.1157^{\mathrm{d}}$ \\
\hline$\%$ mature at age & See ref..$^{g}$ & See ref. ${ }^{b}$ & See ref. ${ }^{c}$ & See ref $^{\mathrm{d}}$ \\
\hline Fecundity at age & See ref. ${ }^{\mathrm{a}}$ & See ref. ${ }^{b}$ & See ref. ${ }^{\mathrm{c}}$ & n.a. \\
\hline Annual recruitment of Age- 2 hake, $H_{2}(t)$ & n.a. & n.a. & n.a. & See ref. ${ }^{d}$ \\
\hline 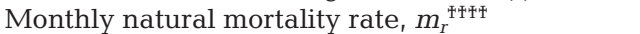 & $0.01042^{\mathrm{a}}$ & $0.005-0.0075^{\mathrm{t}+\mathrm{x}}$ & $0.00611^{\mathrm{c}}$ & $0.01917^{\mathrm{d}}$ \\
\hline Monthly larval mortality rate (Jan. 1 -Apr. 1 ), $m_{l}$ & $4.4234^{\mathrm{f \mp T}}$ & $4.7550^{\text {Ғ¥ษ }}$ & $4.1113^{\text {f丹干 }}$ & n.a. \\
\hline Gear selectivity, $g$ & See ref. ${ }^{a}$ & See ref. ${ }^{b}$ & See ref. ${ }^{c}$ & See ref. ${ }^{\mathrm{d}}$ \\
\hline \multicolumn{5}{|l|}{ Predation (April 1 to November 1 only) } \\
\hline$\%$ of hake diet at $S=1$ & $0.0004^{\mathrm{IIT}}$ & $0.00017^{ \pm+1}$ & $0.00003^{\text {Ғ๘t }}$ & n.a. \\
\hline Age classes vulnerable to hake & $0^{\mathrm{x \Psi}+}$ & $0^{\text {千¥干 }}$ & $0,1^{\text {Ғ¥干 }}$ & n.a. \\
\hline \multicolumn{5}{|l|}{ Management decision rules } \\
\hline Max. annual fishing mortality rate & $0.0283^{\mathrm{a}}$ & $0.0271^{\mathrm{b}}$ & $0.046^{\mathrm{c}}$ & $0.243^{\mathrm{d}}$ \\
\hline Current rockfish SSB / unfished SSB & $0.310^{\mathrm{a}}$ & $0.094^{\mathrm{b}}$ & $0.167^{\mathrm{c}}$ & n.a. \\
\hline Target rebuilding time $(\mathrm{yr})$ & $28^{\mathrm{a}}$ & $70^{\mathrm{b}}$ & $25^{\mathrm{c}}$ & n.a. \\
\hline
\end{tabular}

${ }^{\oplus} \mathrm{FL}-\mathrm{W}$ is the conversion from fork length $(\mathrm{cm})$ to weight $(\mathrm{g})$, which has the form $W=a \times \mathrm{FL}^{b}$. ${ }^{\mathrm{t}+}$ Indicates a smoothed

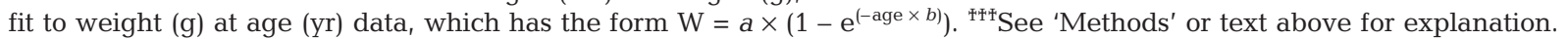
${ }^{\mp \mp \mp 1}$ Mortality rates of age classes vulnerable to hake predation are adjusted during potential feeding months (see 'Methods') 